\title{
Food intake of young people with a migration background living in Germany
}

\author{
Christina Kleiser ${ }^{1}$, Gert BM Mensink ${ }^{1, *}$, Hannelore Neuhauser ${ }^{1}$, Liane Schenk ${ }^{2}$ and \\ Bärbel-Maria Kurth ${ }^{1}$ \\ ${ }^{1}$ Robert Koch Institute, Department of Epidemiology and Health Reporting, PO Box 650261, D-13302 Berlin, \\ Germany: ${ }^{2}$ Charité Center 1: Health and Human Sciences, Institute of Medical Sociology, Berlin, Germany
}

Submitted 7 July 2008: Accepted 25 June 2009: First published online 6 August 2009

\begin{abstract}
Objective: To explore the food intake of young migrants living in Germany. Design: Children and adolescents aged 0 to 17 years living in Germany, including $17 \cdot 1 \%$ with a migration background, were examined in a representative health survey. Food frequency data of 7186 boys and 6919 girls, aged 3 to 17 years, were analysed separately for Turkish, Russian Germans, other migrants and nonmigrants. Daily food intake was calculated and a healthy diet score was used to allow an overall interpretation of the diet. Using stepwise linear regression, the association between migrant status and healthy diet score was analysed.

Results: Turkish participants ( $4 \cdot 8 \%)$ consumed significantly more soft drinks, fried potatoes, chocolate cream and snacks than all other groups and significantly less meat than other migrants and non-migrants. Turkish as well as other migrants $(8.8 \%)$ ate more poultry, fish and pasta/rice, and less sausage/bacon and cooked potatoes, than Russian Germans and non-migrants. Russian Germans (3.5\%) consumed less cooked vegetables than non-migrants and other migrants. Nonmigrants had a better mean dietary score than Russian Germans and other migrants. A less preferable diet score was associated with higher age, male sex, being a migrant from Russia, low or middle socio-economic status, and living in rural or provincial areas.

Conclusions: The study showed considerable differences in dietary habits between young persons of different origin. This underlines the importance of focusing on ethnic groups in dietary interventions.
\end{abstract}

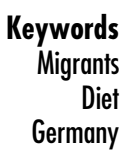

There has been has a long history of migration in Germany since the 17th century. Early, many Germans immigrated to Russia. During World War II their offspring settled in Siberia and Kazakhstan. Meanwhile many of them returned to Germany. In the 1950s, a large group of foreign workers from Southern Europe immigrated and were consequentially followed by their families. In the 1990s, migration streams were modified by the 'fall of the iron curtain' and the civil war in the former Yugoslavia, bringing re-settlers from the Eastern Bloc and refugees to Germany. Hence, the migrant population in Germany is a heterogeneous group, with a majority coming from Turkey and the former Soviet Union. Currently, more than 7 million foreigners (9\% of the population) and about 12 million Germans with a migration background (10\% of the population) live in Germany, which results in a rate of $19 \%$ of the overall population ${ }^{(1)}$.

Health-related risks and health behaviour are affected by cultural influences. Important aspects of dietary habits develop very early in life and mostly persist until adulthood $^{(2,3)}$. Sustainable changes in life, for example migration, can influence these dietary patterns. However, little is known about the dietary habits of migrants, in particular among children and adolescents. Previous studies show several changes in eating habits after migration, but in different directions. Some investigators determined healthier dietary patterns among migrants ${ }^{(4,5)}$, others in the local population ${ }^{(6)}$. Data among migrants in The Netherlands showed for example that children from Morocco and Turkey ate fish and rice or pasta more often, and meat and soft drinks less often, than Dutch children. Furthermore, Turkish/Moroccan children skipped breakfast more often than children of Dutch origin ${ }^{(7)}$. As shown in a recent twin study, even migration from Finland to Sweden was significantly associated with changes in dietary pattern ${ }^{(8)}$. The aim of the present study was to determine the specific food intake of children and adolescents living in Germany with different migrant status from a representative sample. 


\section{Methods}

In KiGGS (German Health Interview and Examination Survey for Children and Adolescents), nationwide representative data of 17641 children and adolescents aged 0 to 17 years were collected between May 2003 and May 2006 in 167 sample points. The sample was drawn in a two-stage procedure. In the first step, sample points were randomly selected with regard to federal state and community size. In these points, random samples of participants were selected stratified by age. The study design and methods have been described in detail elsewhere ${ }^{(9)}$. All participants were interviewed and investigated comprehensively about their health, health behaviour and sociodemographic characteristics. All parents and participants aged 11 years or older were asked to fill in a selfadministered questionnaire on health-relevant topics. This questionnaire exists in different versions related to the age of participants and was available in seven different languages (German, Turkish, Russian, SerboCroatian, Arabic, English and Vietnamese). Questions were also asked about nationality, country of birth, year of immigration (of the parents) and language spoken. Furthermore, medical examinations and medical history interviews were conducted by trained medical staff. The survey was approved by the Federal Office for Data Protection and the ethics committee of Charité University of Medicine, Berlin. All parents provided written informed consent. The overall response rate was $66.6 \%$.

A two-sided migration background was assumed using information on nationality, country of birth and language spoken at home under the following conditions: the participants themselves immigrated to Germany; both parents were not born in Germany; or both parents immigrated to Germany or had no German nationality ${ }^{(10)}$. For the presented analyses we grouped them into Turkish, Russian Germans (immigrants of German origin from the former Soviet Union), other migrants (other than Turkish or Russian Germans) and non-migrants. Information on parents' income, occupational status and education was used to quantify socio-economic status (SES), which was categorised into low, medium and high ${ }^{(11)}$. The participants' main residence was assessed and categorised into former West or East Germany. The degree of urbanisation was grouped into five categories: rural (under 5000 inhabitants), small town (from 5000 to under 20000 inhabitants), middle-sized town (from 20000 to under 100000 inhabitants) and urban (100000 or more inhabitants).

A retrospective semi-quantitative FFQ was used to assess dietary habits ${ }^{(12)}$. Two versions of this FFQ (identical in content) exist: one to be filled in by parents of 1- to 10-year-olds and the other to be filled in by the participants aged 11 to 17 years. This questionnaire was available only in German language. The FFQ covered the food frequencies and average portion sizes of forty-five foods in the last few weeks. Answer categories for the frequency questions were identical for all food items: never, once/month, 2-3 times/month, 1-2 times/week, 3-4 times/week, 5-6 times/week, once/d, 2-3 times/d, 4-5 times/d, $>5$ times/d. Portion sizes were divided into five categories; for example, $1 / 4$ portion (or less), 1/2 portion, 1 portion, 2 portions, 3 portions (or more). To standardise the estimation of portion sizes, most were illustrated with pictures. Missing values in the FFQ were handled as follows. If the food frequency was available but portion size was not ( $n$ 1289), the middle category of portion size (usually one portion) was imputed. If both the food frequency and the portion size were missing ( $n$ 1588), the food item was considered to be not consumed (zero). If no food frequency but a portion size was given ( $n$ 66), the food item was considered a missing value. To calculate average food intake, frequencies were recoded into times of servings per month (where 1 month was set equal to 4 weeks); for example, never $=0$, once $/ \mathrm{d}=28$, $>5$ times $/ \mathrm{d}=168$. For frequency bands such as $1-2$ times/d the arithmetic mean was used (1.5). Finally, daily food intake was calculated by multiplication of food frequency and portion size.

\section{Dietary score}

For an overall interpretation of the diet quality of the participants, a dietary scored based on the FFQ items was constructed and is described in detail elsewhere ${ }^{(13)}$. In brief, average food intake of eleven food groups (beverages, fruit, vegetables, bread/cereals, pasta/rice/ potatoes, milk/dairy products, eggs, meat/sausage, fish, butter/margarine, sweets/snacks/sugared drinks) was compared with age- and sex-specific food-based dietary guidelines for children and adolescents ${ }^{(14)}$ by calculating the ratio (food intake divided by recommended intake). Depending on the guidelines to eat plenty, moderate or small amounts of specific foods, each of these food ratios was then allocated with points ranging from zero to 100 for every food group. For each food group maximum points were given when the recommendation was totally met. Finally, these single scores were added together and standardised to a total scale from zero to 100. A higher score value implies a better overall dietary quality.

\section{Statistical analyses}

Statistical analyses refer to children and adolescents aged 3 to 17 years for whom complete data on food intake were available (7186 boys and 6919 girls). For descriptive analyses and comparison of migrant groups, prevalence, means and 95\% confidence intervals were calculated. Finally, a stepwise linear regression model was used to analyse associations between migration background and health quality of the diet. Since the sample is based on a clustered and stratified design, all analyses were performed with complex sample procedures in the SPSS statistical software package version $14 \cdot 0$ (SPSS Inc., Chicago, 
IL, USA). To enhance the representativeness of the sample, a weighting factor was used in the analyses which corrects for the deviances of the net sample to the population structure (at 31 December 2004) concerning age, gender, residence (West Germany, East Germany, Berlin) and nationality $^{(15)}$. All tests were performed two-sided and $P$ values less than 0.05 or non-overlapping confidence intervals were considered to be statistically significant.

\section{Results}

\section{Study population}

From the 17641 children and adolescents participating in KiGGS, $2590(17 \cdot 1 \%$, weighted) had a (two-parent) migration background. In the total KiGGS sample, 726 ( $4.8 \%$, weighted) of participants were of Turkish origin, 518 (3.5\%, weighted) Russian Germans (immigrants of German origin from the former Soviet Union) and 1346 ( $8.8 \%$, weighted) were of other origin (other than Turkish or Russian German). The largest proportion of migrants was Turkish with $28 \cdot 2 \%$, followed by Russian Germans with $20 \cdot 4 \%$. Participants with a migration background more often had low SES compared with nonmigrant participants $(53 \cdot 7 \%$ v. 22.6\%). Turkish boys and girls showed the highest proportion of low SES with $74.7 \%$. The overall response rate was $66 \cdot 6 \%$.

The overall response for the FFQ was 95.4\%. A completed FFQ was available for $97 \cdot 4 \%$ of non-migrants, $90 \cdot 1 \%$ of Russian Germans, $83.9 \%$ of other migrants and $76 \cdot 8 \%$ of Turkish migrants.

There were no statistically significant differences between responders and non-responders according to age group and BMI among the different migrant groups. Among Turkish migrants only, more boys than girls completed the FFQ. However, more Turkish boys than Turkish girls were present in the analysed data set. Among all migrant groups and non-migrants, the proportion of non-responders was higher for participants with low SES compared with those with higher SES (data not shown).

\section{Dietary behaviour}

Table 1 shows the average food intake in grams per day stratified by migrant group. Turkish children and adolescents consumed significantly more soft drinks, tap water, cereals/cornflakes, white bread/rolls, cream cheese, soup, (deep-) fried potatoes, chocolate cream and snacks than all other groups. Furthermore, Turkish participants ate significantly less meat (without poultry and sausage/bacon) than other migrants and non-migrants. Non-migrants ate significantly less fruit, biscuits and chocolate and more frozen vegetables compared with all other groups. Several differences occurred between Turkish migrants and nonmigrants. Turkish children and adolescents ate significantly more cheese, sweets and pudding/rice pudding and drank significantly less milk than non-migrants. Migrants from
Turkey and other migrants ate more poultry, fish and pasta/rice, and less sausage/bacon and cooked potatoes, than migrants from Russia and non-migrants. Turkish children and adolescents consumed significantly more eggs and fast food than Russian Germans and non-migrants, and other migrants consumed more of those food groups than non-migrants. Other migrants and non-migrants ate significantly more cooked vegetables (prepared from fresh vegetables) than participants from Russia. The consumption of vegetables in total (including salad) showed a tendency to a higher consumption in Turkish and non-migrants compared with participants from Russia (not significant). Consumption of vegetables without salad was significantly higher in non-migrants than in Russian Germans. No statistically significant differences were shown in consumption of mineral water, wholegrain bread, preserved fruit, raw vegetables/salad and cake/pastry.

Table 2 shows the key values of the dietary score. The score values showed a normal distribution. The weighted mean value of the score was 55 with a minimum of 19 and a maximum of 94 points. Ten per cent of the children and adolescents had a score value below 41 and another $10 \%$ above 69 . The mean values of this score according to migrant groups are presented in Fig. 1. It showed a $3 \cdot 3$ point higher (better) value for non-migrants compared with Russian German children and adolescents. This difference was statistically significant. The dietary score of non-migrants was also significantly higher than that of other migrants. The small confidence interval of nonmigrants resulted from the higher number of cases.

Figure 2 shows the mean values of the dietary score according to age group and sex. In every ethnic group younger boys and girls showed a better score, on average, than their older counterparts. Girls had a better mean score than boys of the same age, except the 11- to 17year-old Turkish and Russian German migrants. However, these differences were not often statistically significant. Only younger boys from Turkey had a significantly lower (worse) score than non-migrants boys of the same age. Russian German girls aged 11 to 17 years had a significantly lower mean score than similarly aged nonmigrant girls. In general, Turkish and Russian German children and adolescents showed a worse score than other migrants and non-migrants (Fig. 2).

Finally, a stepwise linear regression model was developed with dietary score as the dependent variable (Table 3). If only age, sex and migrant group were considered in the model (model 1), all migrant groups showed a significant association with dietary quality. When additionally SES was included (model 2), only the association with Russian German participants remained statistically significant. The possibility of a less favourable diet was therefore higher with increasing age, for boys, Russian Germans and participants with a low SES. Living in rural areas, small or middle towns was also associated with a less favourable diet (model 3). 
Table 1 Average food intake ( $\mathrm{g} / \mathrm{d}$ ) by migrant group: young migrants (children and adolescents aged 3 to 17 years) living in Germany, 2003-6

\begin{tabular}{|c|c|c|c|c|c|c|c|c|}
\hline & \multicolumn{2}{|c|}{ Turkish } & \multicolumn{2}{|c|}{ Russian Germans } & \multicolumn{2}{|c|}{ Other migrants } & \multicolumn{2}{|c|}{ Non-migrants } \\
\hline & Mean & $95 \% \mathrm{Cl}$ & Mean & $95 \% \mathrm{Cl}$ & Mean & $95 \% \mathrm{Cl}$ & Mean & $95 \% \mathrm{Cl}$ \\
\hline \multicolumn{9}{|l|}{ Beverages } \\
\hline Soft drinks & $489 \cdot 6$ & $413 \cdot 6,565 \cdot 5$ & $334 \cdot 0$ & $282 \cdot 6,385 \cdot 4$ & $316 \cdot 0$ & $275 \cdot 5,356 \cdot 4$ & $343 \cdot 1$ & $322 \cdot 6,363 \cdot 7$ \\
\hline Energy drinks & $24 \cdot 3$ & $11 \cdot 9,36 \cdot 6$ & $11 \cdot 1$ & $7 \cdot 9,14 \cdot 4$ & $22 \cdot 5$ & $16 \cdot 0,29 \cdot 0$ & $18 \cdot 8$ & $16 \cdot 1,21 \cdot 5$ \\
\hline Fruit juice & $372 \cdot 1$ & $305 \cdot 3,438 \cdot 8$ & $271 \cdot 4$ & $226 \cdot 6,316 \cdot 2$ & $361 \cdot 7$ & $321 \cdot 9,401 \cdot 6$ & $436 \cdot 4$ & $416 \cdot 4,456 \cdot 4$ \\
\hline Tap water & $493 \cdot 7$ & $399 \cdot 1,588 \cdot 3$ & 225.0 & $150 \cdot 9,299 \cdot 1$ & $326 \cdot 3$ & $267 \cdot 8,384 \cdot 8$ & 253.5 & $231 \cdot 0,276 \cdot 1$ \\
\hline Mineral water & $682 \cdot 2$ & $566 \cdot 9,797 \cdot 6$ & 428.9 & $340 \cdot 2,517 \cdot 6$ & $666 \cdot 0$ & $589 \cdot 5,742 \cdot 5$ & $565 \cdot 9$ & $536 \cdot 0,595 \cdot 9$ \\
\hline Fruit or herbal tea & $69 \cdot \overline{8}$ & $47 \cdot 8,91 \cdot 9$ & $78 \cdot 3$ & $52 \cdot 9,103 \cdot 7$ & 83.9 & $67 \cdot 7,100 \cdot 1$ & $100 \cdot 5$ & $92 \cdot 3,108 \cdot 8$ \\
\hline Black or green tea & $105 \cdot 4$ & $80 \cdot 3,130 \cdot 5$ & $98 \cdot 2$ & $69 \cdot 1,127 \cdot 2$ & $42 \cdot 1$ & $32 \cdot 4,51 \cdot 8$ & $14 \cdot 3$ & $10 \cdot 0,18 \cdot 6$ \\
\hline Coffee & $15 \cdot 1$ & $7 \cdot 5,22 \cdot 7$ & $16 \cdot 9$ & $10 \cdot 0,23 \cdot 7$ & $13 \cdot 6$ & $9 \cdot 1,18 \cdot 2$ & $14 \cdot 2$ & $12 \cdot 4,16 \cdot 0$ \\
\hline \multicolumn{9}{|l|}{ Crop products } \\
\hline Fresh fruit & $277 \cdot 8$ & $242 \cdot 6,313 \cdot 1$ & $307 \cdot 3$ & $267 \cdot 2,347 \cdot 4$ & $237 \cdot 4$ & $217 \cdot 4,257 \cdot 4$ & $209 \cdot 1$ & $201 \cdot 7,216 \cdot 5$ \\
\hline Preserved fruit & $10 \cdot 5$ & $5 \cdot 1,15 \cdot 9$ & $8 \cdot 3$ & $6 \cdot 0,10 \cdot 7$ & $6 \cdot 4$ & $4 \cdot 8,8 \cdot 0$ & $8 \cdot 2$ & $7 \cdot 6,8 \cdot 7$ \\
\hline Cooked vegetables & $37 \cdot 3$ & $29 \cdot 6,44 \cdot 9$ & $26 \cdot 8$ & $22 \cdot 1,31 \cdot 6$ & $45 \cdot 2$ & $41 \cdot 0,49 \cdot 4$ & $42 \cdot 5$ & $40 \cdot 9,44 \cdot 1$ \\
\hline Frozen vegetables & $12 \cdot 0$ & $7 \cdot 5,16 \cdot 5$ & $6 \cdot 3$ & $4 \cdot 1,8 \cdot 6$ & $14 \cdot 4$ & $12 \cdot 0,16 \cdot 9$ & $18 \cdot 1$ & $17 \cdot 2,19 \cdot 1$ \\
\hline Preserved vegetables & $9 \cdot 6$ & $6 \cdot 5,12 \cdot 7$ & $9 \cdot 1$ & $6 \cdot 2,11 \cdot 9$ & $8 \cdot 2$ & $5 \cdot 7,10 \cdot 6$ & $10 \cdot 7$ & $9 \cdot 8,11 \cdot 6$ \\
\hline Raw vegetables or salad & $66 \cdot 8$ & $53 \cdot 6,80 \cdot 1$ & $65 \cdot 7$ & $50 \cdot 0,81 \cdot 3$ & $54 \cdot 5$ & $49 \cdot 6,59 \cdot 5$ & $55 \cdot 3$ & $53 \cdot 1,57 \cdot 5$ \\
\hline Vegetables in total & $26 \cdot 4$ & $105 \cdot 8,147 \cdot 0$ & $108 \cdot 2$ & $89 \cdot 9,126 \cdot 5$ & $122 \cdot 1$ & $114 \cdot 0,130 \cdot 2$ & $126 \cdot 7$ & $123.9,129 \cdot 6$ \\
\hline Vegetables (without salad) & $58 \cdot 7$ & $45 \cdot 7,71 \cdot 7$ & $42 \cdot 3$ & $35 \cdot 5,49 \cdot 2$ & $67 \cdot 8$ & $61 \cdot 6,73 \cdot 9$ & $71 \cdot 4$ & $68 \cdot 7,74 \cdot 0$ \\
\hline Pasta or rice & $70 \cdot 1$ & $56 \cdot 8,83 \cdot 4$ & $42 \cdot 6$ & $38 \cdot 0,47 \cdot 2$ & $65 \cdot 2$ & $57 \cdot 7,72 \cdot 7$ & $49 \cdot 1$ & $47 \cdot 3,50 \cdot 8$ \\
\hline Cooked potatoes & $42 \cdot 7$ & $36 \cdot 5,48 \cdot 8$ & $72 \cdot 5$ & $63 \cdot 0,81 \cdot 9$ & $57 \cdot \overline{8}$ & $51 \cdot 2,64 \cdot 5$ & $75 \cdot 5$ & $71 \cdot 6,79 \cdot 4$ \\
\hline \multicolumn{9}{|l|}{ Cereal products and bread } \\
\hline Cereals or cornflakes & $32 \cdot 5$ & $27 \cdot 7,37 \cdot 3$ & $19 \cdot 9$ & $16 \cdot 5,23 \cdot 2$ & $24 \cdot 4$ & $21 \cdot 7,27 \cdot 1$ & $23 \cdot 1$ & $22 \cdot 1,24 \cdot 1$ \\
\hline Wholegrain bread & $59 \cdot 5$ & $50 \cdot 0,69 \cdot 0$ & $54 \cdot 5$ & $42 \cdot 0,66 \cdot 9$ & $50 \cdot 8$ & $45 \cdot 4,56 \cdot 1$ & $56 \cdot 2$ & $53 \cdot 8,58 \cdot 5$ \\
\hline White bread or rolls & $110 \cdot 7$ & $97 \cdot 2,124 \cdot 3$ & $78 \cdot 0$ & $68 \cdot 3,87 \cdot 7$ & $81 \cdot 4$ & $73 \cdot 9,88 \cdot 9$ & $67 \cdot 8$ & $65 \cdot 0,70 \cdot 5$ \\
\hline \multicolumn{9}{|l|}{ Milk and dairy products } \\
\hline Milk & $199 \cdot 3$ & $176 \cdot 4,222 \cdot 1$ & $225 \cdot 1$ & $183 \cdot 8,266 \cdot 4$ & $229 \cdot 9$ & $209 \cdot 9,249 \cdot 9$ & $250 \cdot 9$ & $241 \cdot 3,260 \cdot 5$ \\
\hline Cheese & $32 \cdot 1$ & $26 \cdot 2,38 \cdot 0$ & $23 \cdot 2$ & $17 \cdot 9,28 \cdot 5$ & $24 \cdot 4$ & $21 \cdot 3,27 \cdot 5$ & $21 \cdot 8$ & $20 \cdot 8,22 \cdot 7$ \\
\hline Curd or yoghurt & $121 \cdot 6$ & $100 \cdot 3,142 \cdot 9$ & $111 \cdot 5$ & $95 \cdot 3,127 \cdot 8$ & $119 \cdot 3$ & $107 \cdot 4,131 \cdot 3$ & $112 \cdot 2$ & $108 \cdot 7,115 \cdot 8$ \\
\hline Cream cheese & $16 \cdot 2$ & $12 \cdot 8,19 \cdot 6$ & $6 \cdot 0$ & $3.5,8.5$ & $6 \cdot 2$ & $5 \cdot 3,7 \cdot 1$ & $4 \cdot 7$ & $4 \cdot 5,5 \cdot 0$ \\
\hline Pudding or rice pudding & $28 \cdot 2$ & $20 \cdot 6,35 \cdot 8$ & $17 \cdot 9$ & $11 \cdot 7,24 \cdot 2$ & $21 \cdot 5$ & $18 \cdot 2,24 \cdot 8$ & $18 \cdot 7$ & $17 \cdot 7,19 \cdot 7$ \\
\hline \multicolumn{9}{|l|}{ Meat, sausage and fish } \\
\hline Meat & $27 \cdot 1$ & $22 \cdot 2,32 \cdot 0$ & $36 \cdot 1$ & $30 \cdot 6,41 \cdot 5$ & $41 \cdot 5$ & $37 \cdot 2,45 \cdot 8$ & $35 \cdot 2$ & $33 \cdot 9,36 \cdot 5$ \\
\hline Poultry & $32 \cdot 6$ & $28 \cdot 1,37 \cdot 1$ & $24 \cdot 9$ & $22 \cdot 1,27 \cdot 8$ & $32 \cdot 3$ & $28 \cdot 3,36 \cdot 3$ & $21 \cdot 5$ & $20 \cdot 7,22 \cdot 4$ \\
\hline Sausage or bacon & $19 \cdot 9$ & $16 \cdot 2,23 \cdot 6$ & $45 \cdot 8$ & $38 \cdot 8,52 \cdot 9$ & $31 \cdot 2$ & $28 \cdot 5,34 \cdot 0$ & $43 \cdot 3$ & $42 \cdot 0,44 \cdot 7$ \\
\hline Fish & $14 \cdot 3$ & $12 \cdot 0,16 \cdot 6$ & $10 \cdot 6$ & $9 \cdot 2,12 \cdot 1$ & $14 \cdot 2$ & $12 \cdot 5,15 \cdot 9$ & $10 \cdot 5$ & $10 \cdot 0,11 \cdot 1$ \\
\hline \multicolumn{9}{|l|}{ Fast food, snacks and sweets } \\
\hline Fried potatoes or chips & $42 \cdot 3$ & $36 \cdot 3,48 \cdot 4$ & $17 \cdot 6$ & $14 \cdot 9,20 \cdot 2$ & $28 \cdot 2$ & $25 \cdot 2,31 \cdot 3$ & $17 \cdot 0$ & $16 \cdot 0,17 \cdot 9$ \\
\hline Fast food ${ }^{\star}$ & $13 \cdot 6$ & $11 \cdot 4,15 \cdot 8$ & $8 \cdot 8$ & $7 \cdot 0,10 \cdot 6$ & $10 \cdot 7$ & $9 \cdot 3,12 \cdot 1$ & $7 \cdot 0$ & $6 \cdot 7,7 \cdot 3$ \\
\hline Cake or pastry & $26 \cdot 6$ & $21 \cdot 6,31 \cdot 5$ & $25 \cdot 5$ & $20 \cdot 9,30 \cdot 2$ & $24 \cdot 5$ & $21 \cdot 6,27 \cdot 3$ & $22 \cdot 8$ & $21 \cdot 8,23 \cdot 8$ \\
\hline Biscuits & $6 \cdot 4$ & $5 \cdot 3,7 \cdot 5$ & $7 \cdot 1$ & $5 \cdot 6,8 \cdot 5$ & $6 \cdot 8$ & $5 \cdot 8,7 \cdot 8$ & $4 \cdot 6$ & $4 \cdot 4,4 \cdot 8$ \\
\hline Chocolate & $48 \cdot 0$ & $37 \cdot 8,58 \cdot 1$ & $30 \cdot 4$ & $22 \cdot 8,37 \cdot 9$ & $30 \cdot 0$ & $24 \cdot 9,35 \cdot 1$ & $19 \cdot 1$ & $17 \cdot 9,20 \cdot 2$ \\
\hline Sweets & 9.5 & $8 \cdot 2,10 \cdot 7$ & $9 \cdot 3$ & $8 \cdot 0,10 \cdot 7$ & $8 \cdot 4$ & $7 \cdot 3,9 \cdot 6$ & $7 \cdot 6$ & $7 \cdot 2,7 \cdot 9$ \\
\hline Ice cream & $55 \cdot 9$ & $45 \cdot 0,66 \cdot 8$ & $43 \cdot 2$ & $36 \cdot 1,50 \cdot 2$ & $41 \cdot 0$ & $32 \cdot 6,49 \cdot 5$ & $31 \cdot 6$ & $28 \cdot 9,34 \cdot 2$ \\
\hline Honey or jam & $5 \cdot 1$ & $4 \cdot 2,6 \cdot 0$ & $4 \cdot 4$ & $3 \cdot 6,5 \cdot 3$ & $4 \cdot 2$ & $3 \cdot 5,5 \cdot 0$ & $5 \cdot 2$ & $5 \cdot 0,5 \cdot 5$ \\
\hline Chocolate cream & $9 \cdot 9$ & $7 \cdot 7,12 \cdot 2$ & $4 \cdot 3$ & $2 \cdot 2,6 \cdot 4$ & $4 \cdot 1$ & $3 \cdot 6,4 \cdot 6$ & $6 \cdot 2$ & $5 \cdot 9,6 \cdot 5$ \\
\hline Snacks & $25 \cdot 3$ & $17 \cdot 5,33 \cdot 1$ & $12 \cdot 0$ & $8 \cdot 1,15 \cdot 9$ & $12 \cdot 1$ & $10 \cdot 3,13 \cdot 9$ & $7 \cdot 6$ & $7 \cdot 2,7 \cdot 9$ \\
\hline Nuts & $4 \cdot 5$ & $1 \cdot 3,7 \cdot 7$ & $1 \cdot 2$ & $1 \cdot 0,1 \cdot 5$ & $2 \cdot 0$ & $1 \cdot 5,2 \cdot 4$ & $1 \cdot 1$ & $1 \cdot 0,1 \cdot 1$ \\
\hline \multicolumn{9}{|l|}{ Others } \\
\hline Butter & $4 \cdot 5$ & $3 \cdot 7,5 \cdot 4$ & $4 \cdot 4$ & $3 \cdot 6,5 \cdot 2$ & $4 \cdot 8$ & $4 \cdot 3,5 \cdot 3$ & $5 \cdot 5$ & $5 \cdot 2,5 \cdot 7$ \\
\hline Margarine & $2 \cdot 9$ & $2 \cdot 2,3 \cdot 5$ & $2 \cdot 3$ & $1 \cdot 6,3 \cdot 0$ & $3 \cdot 0$ & $2 \cdot 5,3 \cdot 5$ & 3.9 & $3 \cdot 5,4 \cdot 2$ \\
\hline Ketchup or mayonnaise & $5 \cdot 5$ & $4 \cdot 6,6 \cdot 4$ & $8 \cdot 2$ & $5 \cdot 8,10 \cdot 6$ & $5 \cdot 2$ & $4 \cdot 5,5 \cdot 8$ & $4 \cdot 0$ & $3 \cdot 8,4 \cdot 3$ \\
\hline Eggs & $24 \cdot 8$ & $20 \cdot 6,29 \cdot 1$ & $16 \cdot 1$ & $14 \cdot 1,18 \cdot 1$ & $20 \cdot 2$ & $17 \cdot 3,23 \cdot 1$ & $11 \cdot 4$ & $11 \cdot 0,11 \cdot 7$ \\
\hline Soup & $239 \cdot 5$ & $208 \cdot 3,270 \cdot 7$ & $144 \cdot 9$ & $125 \cdot 2,164 \cdot 7$ & $116 \cdot 5$ & $104 \cdot 9,128 \cdot 0$ & $76 \cdot 1$ & $73 \cdot 0,79 \cdot 2$ \\
\hline Pancake & $10 \cdot 5$ & $7 \cdot 8,13 \cdot 2$ & $20 \cdot 8$ & $16 \cdot 0,25 \cdot 6$ & $15 \cdot 7$ & $12 \cdot 3,19 \cdot 1$ & $11 \cdot 1$ & $10 \cdot 6,11 \cdot 6$ \\
\hline
\end{tabular}

Significant differences between migrant groups (non-overlapping confidence intervals) are highlighted (bold).

*Fried sausage, curry sausage, hamburger, doner kebab.

\section{Discussion}

The analyses of daily food intake indicate considerable migration-specific differences in dietary habits. Overall, Turkish and Russian German migrants showed a less favourable diet compared with non-migrants although some aspects of their eating habits were preferable, for example the higher fruit consumption. On the other hand, Turkish children and adolescents consumed the highest average amounts of soft drinks, white bread and rolls, fried potatoes or potatoes chips, chocolate and snacks. Participants from Russia consumed the lowest amounts of beverages and vegetables (but similar amounts of fruit as the Turkish) and ate the highest 
amounts of sausage or bacon. Non-migrants consumed the lowest amounts of biscuits, chocolate, sweets and snacks. The healthy diet score, which is based on a comparison with the current recommendation, was lowest for Russian Germans. Furthermore, participants with low SES had a lower dietary score. Since children and adolescents with a migration background were disproportionally often

Table 2 Main characteristics of the dietary score: young migrants (children and adolescents aged 3 to 17 years) living in Germany, 2003-6

\begin{tabular}{lc}
\hline Parameter & Value \\
\hline Mean & $55 \cdot 4$ \\
Median & $55 \cdot 5$ \\
Minimum & $19 \cdot 2$ \\
Maximum & $93 \cdot 6$ \\
Percentile 10 & $41 \cdot 4$ \\
Percentile 25 & $48 \cdot 1$ \\
Percentile 75 & $63 \cdot 0$ \\
Percentile 90 & $69 \cdot 3$ \\
Standard deviation & $10 \cdot 8$ \\
Standard error of mean & 0.09 \\
\hline
\end{tabular}

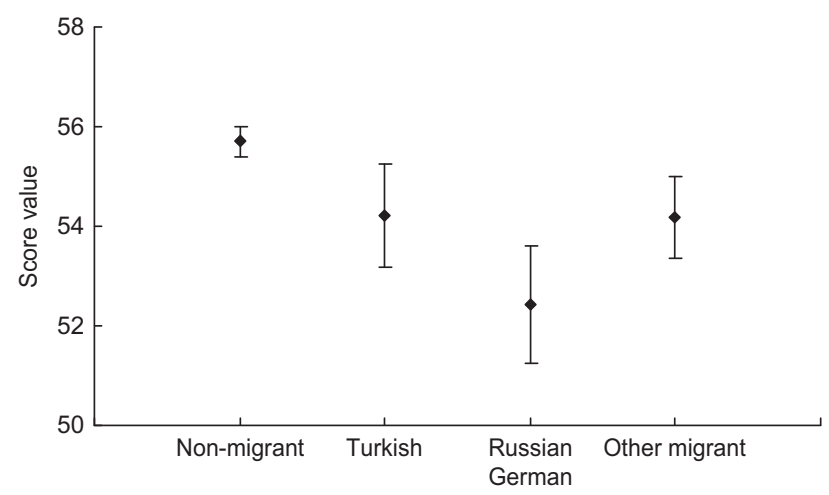

Fig. 1 Dietary score by migrant group: young migrants (children and adolescents aged 3 to 17 years) living in Germany, 2003-6. Values are means with their $95 \%$ confidence intervals represented by vertical bars participants with low SES, we adjusted for SES in our analyses. After adjusting for SES, the association between the dietary score and migration background changed. For example, there was no longer a significant association among Turkish migrants. SES is independently associated with food intake, which may explain part of the association between food intake and migration background. However, in the multiple linear regression models a migrant-specific association with overall diet quality remained, independent of SES.

The results of our study are in line with several former investigations which determined differences in eating habits between migrants and non-migrants ${ }^{(8,16)}$. However, lifestyle and nutrition are influenced by many factors, such as degree of integration, duration of stay, generation of migration and language ability ${ }^{(5,17,18)}$. Some researchers conclude that migrants better meet national recommendations than natives ${ }^{(5,7)}$. For example, the average macronutrient intake of migrant children from Surinam and Mediterranean areas, as well as of Turkish and Moroccan women, was more in line with the Dutch dietary guidelines than the traditional Dutch $\operatorname{diet}^{(7)}$. Furthermore, North African migrant men living in France had a better overall diet quality than natives ${ }^{(19)}$. However, in our analyses migrant children and adolescents, especially Russian Germans and Turkish, were not more likely to eat according to the national recommendation than non-migrants. It seems that migrant children and adolescents have more strongly adapted less preferable aspects of the modern Western diet; for example, indicated by the high consumption of soft drinks, fast food and sweets among Turkish migrants.

Differences in the results of studies focusing on dietary behaviour among migrants may not only strongly reflect the differences in the initial food culture of the major migrant groups, but also the differences in the traditional food culture of the resident countries. Migrant groups differ historically between different countries. For instance, Turkish people are a major migrant group in

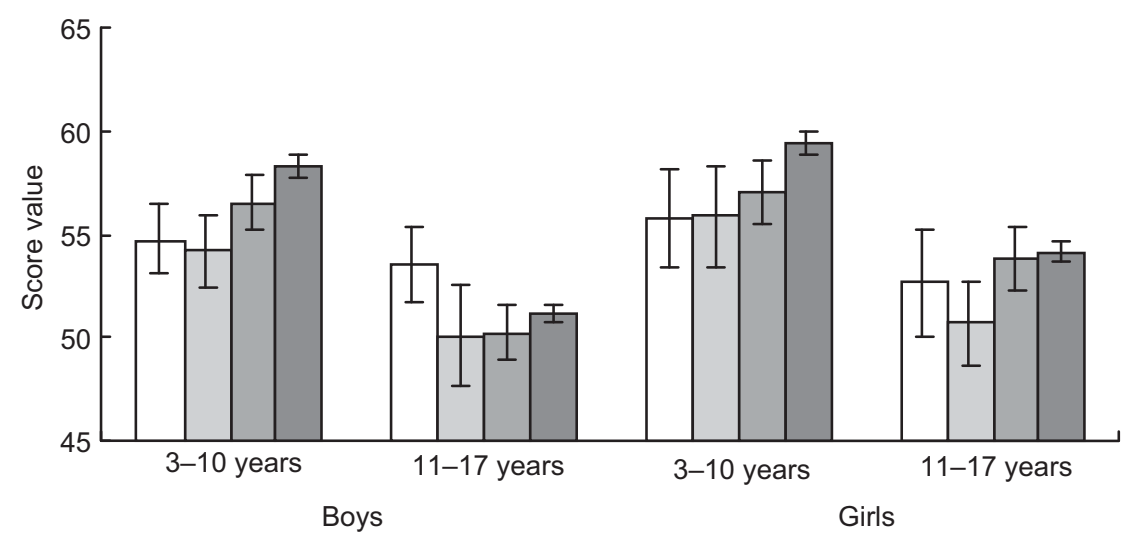

Fig. 2 Dietary score by age group, sex and migrant group ( $\square$, Turkish migrants; $\square$, Russian German migrants; $\square$, other migrants; $\square$, non-migrants): young migrants (children and adolescents aged 3 to 17 years) living in Germany, 2003-6. Values are means with their $95 \%$ confidence intervals represented by vertical bars 
Table 3 Determinants of the dietary score (linear regression models): young migrants (children and adolescents aged 3 to 17 years) living in Germany, 2003-6

\begin{tabular}{|c|c|c|c|c|c|}
\hline & Parameter & Regression coefficient $(B)$ & $95 \% \mathrm{Cl}$ & $P$ value & $R^{2}$ \\
\hline \multirow[t]{8}{*}{ Model 1} & Intercept & $64 \cdot 1$ & $63 \cdot 5,64 \cdot 8$ & $<0.001$ & \\
\hline & Age in years & -0.7 & $-0.8,-0.7$ & $<0.001$ & \\
\hline & Boys & $-2 \cdot 0$ & $-2 \cdot 4,-1 \cdot 5$ & $<0.001$ & \\
\hline & Girls (Ref) & - & - & - & \\
\hline & Turkish & $-1 \cdot 6$ & $-2 \cdot 6,-0.5$ & 0.003 & \\
\hline & Russian German & $-3 \cdot 0$ & $-4 \cdot 1,-1 \cdot 8$ & $<0.001$ & \\
\hline & Other migrant & $-1 \cdot 3$ & $2 \cdot 2,0 \cdot 5$ & 0.003 & \\
\hline & Non-migrant (Ref) & - & - & - & 0.096 \\
\hline \multirow[t]{11}{*}{ Model 2} & Intercept & $66 \cdot 2$ & $65 \cdot 5,66 \cdot 9$ & $<0.001$ & \\
\hline & Age in years & -0.7 & $-0.8,-0.7$ & $<0.001$ & \\
\hline & Boys & $-2 \cdot 0$ & $-2 \cdot 4,-1 \cdot 6$ & $<0.001$ & \\
\hline & Girls (Ref) & - & - & - & \\
\hline & Turkish & $-1 \cdot 3$ & $-1 \cdot 3,0 \cdot 9$ & $0 \cdot 768$ & \\
\hline & Russian German & $-3 \cdot 2$ & $-3.2,-0.9$ & 0.001 & \\
\hline & Other migrant & $-1 \cdot 6$ & $-1 \cdot 6,0 \cdot 2$ & $0 \cdot 141$ & \\
\hline & Non-migrant (Ref) & - & - & - & \\
\hline & Low SES & $-4 \cdot 6$ & $-4 \cdot 6,-3 \cdot 4$ & $<0.001$ & \\
\hline & Middle SES & $-3 \cdot 2$ & $-3 \cdot 2,-2 \cdot 2$ & $<0.001$ & \\
\hline & High SES (Ref) & - & - & - & 0.114 \\
\hline \multirow[t]{15}{*}{ Model 3} & Intercept & $66 \cdot 9$ & $66 \cdot 1,67 \cdot 6$ & $<0.001$ & \\
\hline & Age in years & -0.7 & $-0.75,-0.7$ & $<0.001$ & \\
\hline & Boys & $-2 \cdot 0$ & $-2 \cdot 4,-1 \cdot 5$ & $<0.001$ & \\
\hline & Girls (Ref) & - & - & - & \\
\hline & Turkish & -0.5 & $-1 \cdot 6,0 \cdot 6$ & 0.350 & \\
\hline & Russian German & $-2 \cdot 2$ & $-3 \cdot 4,-1 \cdot 0$ & $<0.001$ & \\
\hline & Other migrant & $-1 \cdot 0$ & $-1 \cdot 9,-0 \cdot 1$ & 0.031 & \\
\hline & Non-migrant (Ref) & - & - & - & \\
\hline & Low SES & -3.9 & $-4 \cdot 5,-3 \cdot 3$ & $<0.001$ & \\
\hline & Middle SES & $-2 \cdot 6$ & $-3 \cdot 1,-2 \cdot 1$ & $<0.001$ & \\
\hline & High SES (Ref) & - & - & - & \\
\hline & Rural & $-1 \cdot 2$ & $-2 \cdot 1,-0.4$ & 0.005 & \\
\hline & Small town & $-1 \cdot 1$ & $-1 \cdot 7,-0 \cdot 4$ & 0.002 & \\
\hline & Middle-sized town & $-0 \cdot 7$ & $-1.4,0.0$ & 0.038 & \\
\hline & Urban (Ref) & - & - & - & $0 \cdot 115$ \\
\hline
\end{tabular}

Ref, reference group; SES, socio-economic status.

Germany, whereas in France a large proportion of migrants are African. Therefore, a cross-national comparison is difficult. Next to the cultural differences, differences in national food guidelines and evaluation tools make comparisons of results complicated. For instance, our dietary score is strongly based on national recommendations and is a relatively subjective instrument.

The strengths of our study include the large sample size and national representativeness across a wide age range, its good response rate for migrants and non-migrants, and the detailed information on the migration background and on food habits. In KiGGS specific effort was made in the study design to adequately integrate persons with a migration background. For example, the main questionnaires were available in seven different languages ${ }^{(10)}$. The proportion of migrants of $17 \%$ in the study population reflects a good representativeness of the overall migrant population living in Germany (currently 19\%). However, our study does not claim to be representative for all migrant groups. Furthermore, the FFQ exists in German only and contains a limited number of items. It may be that some items in the FFQ are less sensitive for the special food habits of migrants. More open-ended instruments such as food records or $24 \mathrm{~h}$ recalls may be more culture-specific. However, the food groups in the FFQ are relatively broad so it may be assumed that, on this rough level, it may assess intake in a standardised and comparable way. Probably since the FFQ was not translated, a lower completion rate was seen among migrants in comparison to non-migrants. Furthermore, there was an overall lower response for children and adolescents with low SES. Although we adjusted for SES in the multivariable analysis, this could result in an underestimation of differences between migrants and non-migrants.

In conclusion, our results suggest that there are several differences in the dietary habits of children and adolescents with different migration background. This finding is of public health relevance since migrant children are not only a large but also a vulnerable population group. Furthermore, their lower SES interrelates not only with their nutrition but also with other health-related factors. Since dietary habits formed in childhood are often preserved throughout life and are of importance for a variety of lifestyle-related diseases, positive dietary habits need to be recognised and strengthened while unhealthy diets need to be prevented as early as possible. A nutritionally 
valuable diet with plenty of fruit, vegetables and carbohydrate-rich foods is an important health-promoting resource and should be strengthened. The disadvantages of supposed modern Western nutrition should be highlighted and made a subject of discussion. There is a need to set special focus points in promoting of healthy dietary behaviour among children and adolescents with a migration background.

\section{Acknowledgements}

KiGGS was funded by the German Federal Ministry of Health, the German Federal Ministry of Education and Research, and the Robert Koch Institute. The present analyses were supported by the German Federal Ministry of Food, Agriculture and Consumer Protection. None of the authors had any conflict of interest. All authors contributed to interpretation of the data and revision of the manuscript.

\section{References}

1. Statistisches Bundesamt (2006) Leben in Deutschland. Haushalte, Familien und Gesundheit - Ergebnisse des Mikrozensus 2005, pp. 73-99. Wiesbaden: Statistisches Bundesamt.

2. Birch LL \& Fischer JO (1998) Development of eating behaviours among children and adolescents. Pediatrics 101, 539-549.

3. Leach H (1999) Food habits. In Essentials of Human Nutrition, pp. 515-521 [J Mann and AS Truswell, editors]. Oxford/New York/Tokyo: Oxford University Press.

4. Gedrich K \& Karg G (2001) Dietary habits of Germans versus non-German residents in Germany. In Culinary Arts and Sciences III - Global and National Perspectives, pp. 419-428 [J Edwards and M Hewedi, editors]. Bournemouth: Worshipful Company of Cooks Centre for Culinary Research at Bournemouth University.

5. Darmon N \& Khlat M (2001) An overview of the health status of migrants in France, in relation to their dietary practices. Public Health Nutr 4, 163-172.

6. Bau AM, Matteucci Gothe R \& Borde T (2003) Ernährungsverhalten von 3- bis 6-jährigen Kindern verschiedener Ethnien - Ergebnisse einer Kitastudie in Berlin. Ernabrungs Umsch 50, 214-218.

7. Brussaard JH, van Erp-Baart MA, Brants HAM, Hulshof KFAM \& Löwik MRH (2001) Nutrition and health among migrants in the Netherlands. Public Health Nutr 4, 659-664.
8. Hammar N, Hakala P, Jorgensen L, Becker W, Hedlund E, Ronnemaa T, Koskenvuo M \& Kaprio J (2009) Migration and differences in dietary habits-a cross sectional study of Finnish twins in Sweden. Eur J Clin Nutr 63, 312-322.

9. Kurth B, Kamtsiuris P, Hoelling $\mathrm{H}$ et al. (2008) The challenge of comprehensively mapping children's health in a nation-wide health survey: design of the German KiGGS-Study. BMC Public Health 8, 196.

10. Schenk L, Ellert U \& Neuhauser H (2007) Children and adolescents with a migration background. Methodical aspects in the German Health Interview and Examination Survey for Children and Adolescents (KiGGS). Bundesgesundheitsblatt Gesundheitsforschung Gesundheitsschutz 50, 590-599.

11. Lange M, Kamtsiuris P, Lange C, Schaffrath Rosario A, Stolzenberg H \& Lampert T (2007) Sociodemographic characteristics in the German Health Interview and Examination Survey for Children and Adolescents (KiGGS) - operationalisation and public health significance, taking as an example the assessment of general state of health. Bundesgesundheitsblatt Gesundheitsforschung Gesundheitsschutz 50, 578-589.

12. Mensink GBM \& Burger M (2004) What do you eat? Food frequency questionnaire for children and adolescents. Bundesgesundheitsblatt Gesundheitsforschung Gesundbeitsschutz 47, 219-226.

13. Kleiser C, Mensink G, Scheidt-Nave C \& Kurth B (2009) HuSKY: a healthy nutrition score based on food intake of children and adolescents in Germany. Br J Nutr (Epublication ahead of print version).

14. Kersting M, Alexy U \& Clausen K (2005) Using the concept of food based dietary guidelines to develop an optimized mixed diet (OMD) for German children and adolescents. J Pediatr Gastroenterol Nutr 40, 301-308.

15. Kamtsiuris P, Lange M \& Schaffrath Rosario A (2007) The German Health Interview and Examination Survey for Children and Adolescents (KiGGS): sample design, response and nonresponse analysis. Bundesgesundheitsblatt Gesundheitsforschung Gesundheitsschutz 50, 547-555.

16. Landman J \& Cruickshank JK (2001) A review of ethnicity, health and nutrition-related diseases in relation to migration in the United Kingdom. Public Health Nutr 4, 647-657.

17. Pan YL, Dixon Z, Himburg S \& Huffman F (1999) Asian students change their eating patterns after living in the United States. J Am Diet Assoc 99, 54-57.

18. Lee SK, Sobal J \& Frongillo EA (1999) Acculturation and dietary practices among Korean Americans. J Am Diet Assoc 99, 1084-1089.

19. Méjean C, Traissac P, Eymard-Duvernay S, El Ati J, Delpeuch F \& Maire B (2007) Diet quality of North African migrants in France partly explains their lower prevalence of diet-related chronic conditions relative to their native French peers. J Nutr 137, 2106-2113. 